\title{
Distance Traveled to a Fetal Center and Pregnancy Outcomes in Twin-Twin Transfusion Syndrome
}

\author{
Eric P. Bergh ${ }^{a}$ Roopali Donepudi ${ }^{b}$ Cynthia S. Bell ${ }^{c}$ Kenneth J. Moise Jr. ${ }^{a}$ \\ Anthony Johnson ${ }^{\text {a }}$ Ramesha Papanna ${ }^{a}$ \\ aThe Fetal Center, Department of Obstetrics, Children's Memorial Hermann Hospital, Gynecology and Reproductive

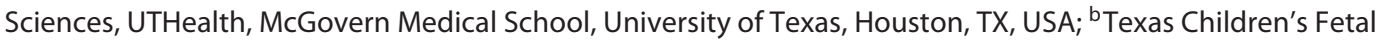 \\ Center, Departments of Obstetrics and Gynecology, Baylor College of Medicine, Houston, TX, USA; ' McGovern \\ Medical School at UTHealth, Center for Clinical Research and Evidence-Based Medicine, Houston, TX, USA
}

\section{Keywords}

Fetal surgery · Fetoscopy · Twin-twin transfusion syndrome $\cdot$ Perinatal outcomes

\begin{abstract}
Background: Fetoscopic laser photocoagulation (FLP) is the definitive treatment for twin-twin transfusion syndrome (TTS). Due to variability in geographic proximity to highvolume fetal centers, many patients travel great distances to receive experienced care. We sought to determine whether distance traveled (DT) is associated with gestational age (GA) at delivery and neonatal survival. Methods: A prospective cohort study of patients within the continental United States referred to our center between September 23, 2011 and July 25, 2018 undergoing planned FLP for TTS ( $n=393$; GA 20.6 \pm 2.5 weeks; stage I: $n=50$; stage II: $n=118$; stage III: $n=208$; stage IV: $n=17$ ) was performed. The great-circle distance to our center was calculated using patients' home zip codes. DT was stratified into groups containing equal patient numbers and pregnancy outcomes assessed. Results: A total of 393 patients met the inclusion criteria. The threshold distance from our center was $<250$ miles $(n=181), 250-499$ miles $(n=$ $119)$, and $\geq 500$ miles $(n=93)$. There was no significant differ-
\end{abstract}

ence between any of the preoperative variables among the three groups, with the exception of race and rural status. Furthermore, there was no significant association between DT and GA at delivery ( $p=0.34)$, time interval from procedure to delivery $(p=0.37)$, and the number of neonatal survivors ( $p=$ 0.21 ). Preterm premature rupture of membranes (PPROM) at $<34$ weeks was highest $(47.9 \%, p=0.04)$ in the group traveling 250-499 miles. Conclusion: To our knowledge, this is the largest study to show that in TTTS, DT is not associated with GA at delivery, time interval from procedure to delivery, or neonatal survival. Although PPROM at $<34$ weeks was higher in the group traveling 250-499 miles, there was no significant difference in GA at delivery. While patients with advanced disease may choose to seek treatment based on proximity, traveling long distances does not adversely affect pregnancy outcomes.

(c) 2019 S. Karger AG, Basel

\section{Introduction}

Twin-twin transfusion syndrome (TTTS) affects approximately $9-15 \%$ of monochorionic diamniotic twin pregnancies $[1,2]$. In the United States approximately karger@karger.com

www.karger.com/fdt

Karger $\stackrel{2}{\circ}$ (c) 2019 S. Karger AG, Base

Section of Maternal-Fetal Medicine, Department of Obstetrics,

Gynecology, and Reproductive Sciences, McGovern School of Medicine, UT Health 6431 Fannin St. Suite 3.274, Houston, TX 77030 (USA)

E-Mail ramesha.papanna@uth.tmc.edu 
$850-1,000$ patients are referred for evaluation of TTTS annually, of whom nearly 400-650 undergo treatment with fetoscopic laser photocoagulation (FLP) at fetal centers reporting to the North American Fetal Treatment Network [3]. Fetal treatment centers are established locations of clinical excellence where an experienced team may provide multidisciplinary care to patients referred for in utero fetal therapy. As of 2014, 22 fetal centers performing FLP were identified in North America; $50 \%$ were designated as high-volume centers reporting $>20$ FLP cases per year [4].

Due to geographic variability, patients referred for treatment of TTTS may travel great distances to an experienced fetal center. Little is known about the impact of long-distance travel in these patients. Travel to distant obstetric providers is associated with increased maternal stress and anxiety [5], financial burden [6], and delays in referral to tertiary care centers [7]. Furthermore, data on risks of air transportation in pregnancy are conflicting with regard to maternal morbidity $[8,9]$ and rates of preterm delivery $[10,11]$. Among patients with TTTS, data are limited to a single study in which 16 patients who traveled to a fetal treatment center by air had no increased incidence of maternal or neonatal morbidity/survival compared to patients who traveled by land [12].

In this study, we evaluated a large cohort of women referred to a single center to determine whether the distance traveled (DT) to a fetal treatment center is associated with adverse delivery and neonatal outcomes.

\section{Subjects and Methods}

\section{Study Design and Patient Population}

This was a prospective cohort study of patients with monochorionic diamniotic twin pregnancies undergoing FLP for TTTS between 16 and 29 weeks gestational age (GA) at The Fetal Center (TFC) at Children's Memorial Hospital in Houston, TX, USA. The study was conducted between September 23, 2011 and July 25, 2018. All patients underwent a detailed preoperative ultrasound examination, including Doppler studies for diagnosis and staging based on Quintero staging, as well as transvaginal ultrasound measurement of cervical length.

All patients received preoperative nifedipine for tocolysis. The fetoscopic laser ablation was performed through a single-port fetoscopy with intravenous sedation and a local anesthetic as previously published by us [13]. The patients who underwent laparoscopy-assisted fetoscopy for an anterior placenta received general anesthesia [14].

This was an intention to treat analysis of all monochorionic diamniotic twin gestations with the diagnosis of TTTS undergoing FLP referred within the continental United States during the study period. The following baseline characteristics were collected: maternal demographics (maternal age, gravidity, parity, body mass index, race, GA at procedure, and rural status), staging using Quintero criteria, cervical length (measured transvaginally), and estimated fetal weight discordance. Operative variables included type of procedure, type of anesthesia, and cannula diameter for trocar entry. Postoperative variables included GA at delivery, procedure to delivery interval, rates of preterm premature rupture of membranes (PPROM) at $<34$ weeks, and neonatal survival.

Composite neonatal morbidity was defined as presence of any of the following: delivery prior to 28 weeks or no neonatal survivors after the first 28 days of life. The great-circle distance from the patients' location of origin to TFC was calculated using GPS coordinates derived from patients' home address zip codes [15]. Rural status was assigned by linking patient zip codes to the Rural Urban Commuting Area (version 3.10) three-tier classification of commuting areas based on the 2010 US Census and the 2006-2010 American Community Survey [16]. The categories include (1) urban core areas, (2) large rural cities/towns, and (3) small and isolated-small rural towns.

\section{Statistics}

Logistic regression and locally weighted polynomial regression were used to estimate the influence of DT on composite neonatal morbidity. Inflection points in the probability of the composite adverse outcome were identified at approximately 250 and 500 miles and defined group 1 (<250 miles) and group 2 (250-499 miles). Patients traveling $\geq 500$ miles were assigned to group 3 . Outcomes between the groups were compared. Normality testing of continuous data was performed using the Shapiro-Wilk normality test.

Results are reported as either percentage or mean with standard deviation or median with interquartile range, as appropriate. Data were compared with $\chi^{2}$ and one-way ANOVA as appropriate for normally distributed data or Kruskal-Wallis and Fisher exact test for nonnormally distributed data. All statistical analyses were performed using $\mathrm{R}$ version 3.5.0 [17]. A $p$ value $<0.05$ was considered significant.

\section{Results}

A total of 396 patients met the inclusion criteria and underwent FLP for TTTS during the study period. In 4 cases of failed FLP, an alternate procedure was performed (amnioreduction in 1 and selective reduction via bipolar cord coagulation in 3). Six patients underwent termination of pregnancy post procedure. Only 3 cases in whom complete delivery and neonatal outcomes were lost to follow-up were excluded. The final cohort included 393 cases for analysis. The median distance to TFC was 271.1 miles (interquartile range 184-473).

Figure 1 shows the impact of DT on the probability of the composite adverse neonatal outcome. Group thresholds were defined as $<250$ miles $(n=181), 250-499$ miles $(n=119)$, and $\geq 500$ miles $(n=93)$. The results of logistic regression analysis are presented in Table 1 and indicate a lack of significant relationship between both the composite outcome and DT or defined distance groups. 
Fig. 1. Locally weighted polynomial regression smoothing curve plotting the probability of composite adverse outcome against distance traveled. Distance thresholds were set at $<250$ miles (group 1), 250-499 miles (group 2), and $\geq 500$ miles (group 3 ).

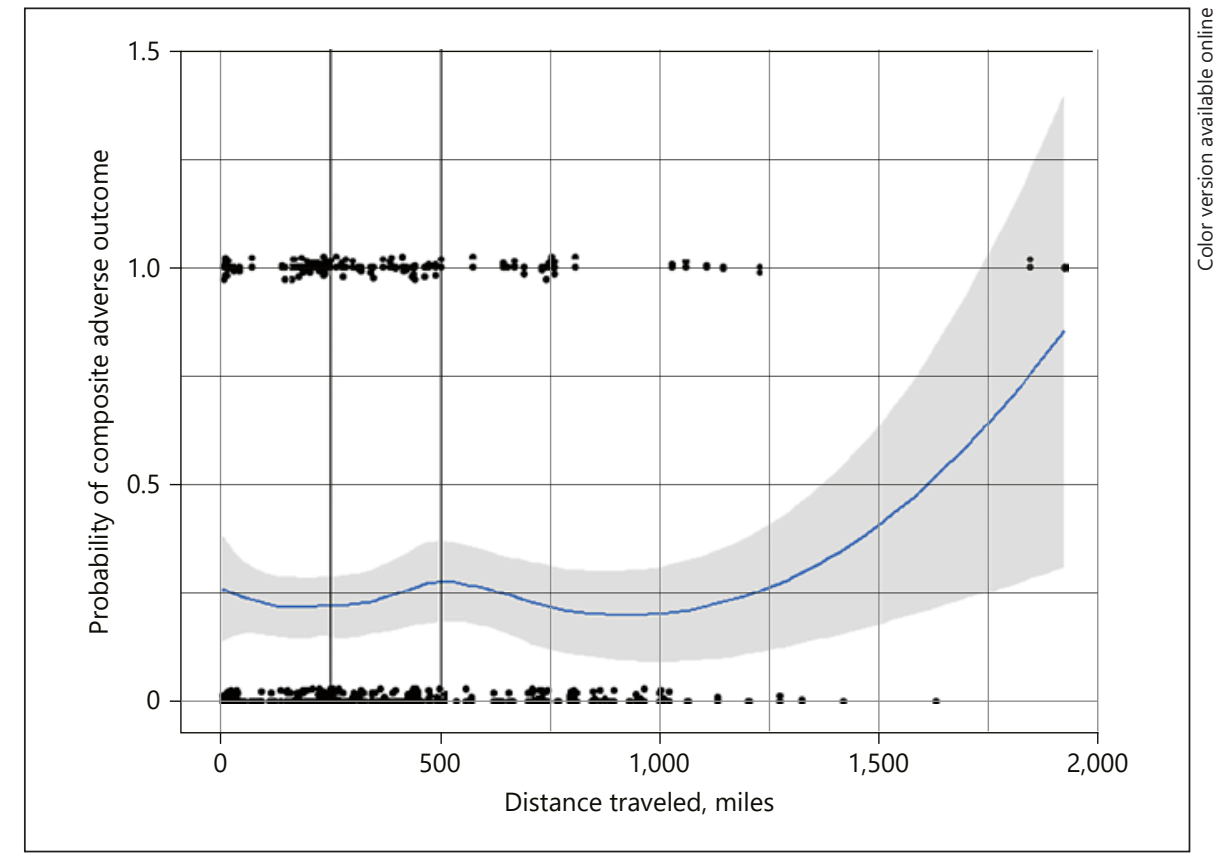

Table 1. Results of logistic regression analysis

\begin{tabular}{|c|c|c|c|c|c|}
\hline Predictor & Estimate & SE & $z$ value & $p$ value & OR \\
\hline Intercept & -1.3003904 & 0.2084287 & -6.239 & $4.4 \times 10^{-8}$ & - \\
\hline Distance to The Fetal Center, miles & 0.0009365 & 0.0007808 & 1.199 & 0.230 & $1.00(0.99-1.00)$ \\
\hline \multicolumn{6}{|l|}{ Radius group $($ reference $=$ group 1$)$} \\
\hline Group 2 & -0.1739321 & 0.3253921 & -0.535 & 0.593 & $1.03(0.6-1.78)$ \\
\hline Group 3 & -0.6854692 & 0.6499332 & -1.055 & 0.292 & $0.99(0.55-1.79)$ \\
\hline
\end{tabular}

The demographic and operative characteristics of the study cohort are presented in Table 2 . With the exception of race and rural status, there was no difference in maternal demographics including maternal age, gravidity, parity, body mass index, GA at procedure, Quintero stage at diagnosis, cervical length, percent estimated fetal weight discordance, procedure type, anesthesia type, or cannula diameter. Compared with group 1, both groups 2 and 3 had significantly fewer patients residing in large urban areas. Groups 2 and 3 also had a significantly larger proportion of people who identified as Caucasian.

Postoperative outcomes are presented in Table 3. There was no difference in time interval from procedure to delivery ( $p=0.33)$, GA at delivery $(p=0.29)$, or number of neonatal survivors beyond 28 days of life $(p=0.21)$. Rates of PPROM at $<34$ weeks were significantly different with the highest rates in group $2(47.9 \%, p=0.04)$.

\section{Discussion}

To our knowledge, this is the largest study to evaluate DT to an experienced fetal treatment center and outcomes in patients with TTTS treated with FLP. The results of this cohort demonstrate that despite increased rates of PPROM in group 2, DT is not associated with differences in GA at delivery, interval from procedure to delivery, or neonatal survival.

Due to the rarity of TTTS, only half of the established fetal centers in North America may be classified as high volume (arbitrarily defined as $>20$ cases/year) [4]. When deciding how to best allocate limited resources for the treatment of a rare disease, the need for geographic proximity to low-volume centers must be balanced against the experience gained from regionalization of care. Previous research in the treatment of TTTS with FLP suggests that the surgical experience gained with regionalization may 
Table 2. Demographic and operative characteristics of the study population

\begin{tabular}{|c|c|c|c|c|}
\hline & group 1 (<250 miles) & group 2 (250-499 miles) & group 3 ( $\geq 500$ miles) & $p$ value \\
\hline Maternal age, years & $29(24-33)$ & $28(24-31)$ & $29(25-33)$ & 0.23 \\
\hline Gravidity & $2(1-10)$ & $2(1-6)$ & $2(1-8)$ & 0.30 \\
\hline Parity (term and preterm births) & $1(0-6)$ & $1(0-5)$ & $0(0-5)$ & 0.30 \\
\hline Distance to TFC, miles & $171.37(26-228)$ & $366.81(297-427)$ & $767.16(710-962)$ & $<0.001$ \\
\hline Quintero stage & & & & 0.20 \\
\hline I & $28(15.5 \%)$ & $15(12.6 \%)$ & $7(7.5 \%)$ & \\
\hline II & $54(29.8 \%)$ & $36(30.3 \%)$ & $28(30.1 \%)$ & \\
\hline III & $95(52.5 \%)$ & $59(49.6 \%)$ & $54(58.1 \%)$ & \\
\hline FLP & $166(91.7 \%)$ & $108(90.8 \%)$ & $86(92.5 \%)$ & \\
\hline Laparoscopy-assisted FLP & $14(7.7 \%)$ & $8(6.7 \%)$ & $7(7.5 \%)$ & \\
\hline Failed laser, alternative procedure & $1(0.6 \%)^{\mathrm{a}}$ & $3(2.5 \%)^{\mathrm{a}, \mathrm{b}}$ & $0(0.0 \%)$ & \\
\hline Anesthesia & & & & 0.20 \\
\hline General & $19(10.5 \%)$ & $7(5.9 \%)$ & $12(12.9 \%)$ & \\
\hline Sedation & $162(89.5 \%)$ & $112(94.1 \%)$ & $81(87.1 \%)$ & \\
\hline Cannula size & & & & 0.48 \\
\hline 9 French & $14(7.7 \%)$ & $7(5.9 \%)$ & $5(5.4 \%)$ & \\
\hline 10 French & $65(35.9 \%)$ & $33(27.7 \%)$ & $29(31.2 \%)$ & \\
\hline 12 French & $102(56.4 \%)$ & $79(66.4 \%)$ & $59(63.4 \%)$ & \\
\hline Rural status & & & & $<0.001$ \\
\hline Urban & $173(95.6 \%)^{*, * *}$ & $95(79.8 \%)^{*}$ & $81(87.1 \%)^{* *}$ & \\
\hline TOP post procedure & $2(1.1 \%)$ & $3(2.5 \%)$ & $1(1.1 \%)$ & 0.57 \\
\hline
\end{tabular}

Data are given as median (range) or $n(\%)$. Kruskal-Wallis test, $\chi^{2}$ test, and Fisher exact test were used as appropriate. FLP, fetoscopic

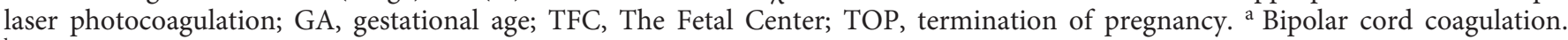
b Amnioreduction only. *, ** Post hoc tests.

lead to improved patient outcomes $[18,19]$. In fact, a previous review of trainees in fetal therapy for TTTS suggests that a minimum of 20 FLP cases under the supervision of an experienced operator are required to attain an acceptable level of surgical competency [20]. The exact number of cases necessary annually to maintain this level of proficiency has not been determined [21]. It is worth noting that the evaluation and management of TTTS is often complicated by atypical presentation and/or progression of disease severity [22]. TTTS is often mimicked or com- plicated by selective intrauterine fetal growth restriction and/or twin anemia polycythemia sequence, for which evaluation and counseling must be individualized [23, 24]. Therefore, experience with navigating the nuances of these distinct diagnoses may be an important factor in deciding when to offer FLP.

Previous analyses of geographic disparities in healthcare have reported estimates of patient travel times based on road networks and travel patterns $[25,26]$. However, as many of our patients both fly and drive to our center, 
Table 3. Postoperative outcomes of the study population

\begin{tabular}{|c|c|c|c|c|}
\hline & group 1 (<250 miles) & group 2 (250-499 miles) & group 3 ( $\geq 500$ miles) & $p$ value \\
\hline Procedure to delivery interval, weeks & $10.7(7-14)$ & $10.6(7-13)$ & $11(8-15)$ & 0.33 \\
\hline GA at delivery, weeks & $31.9(28-34)$ & $31.3(28-34)$ & $32.6(29-35)$ & 0.29 \\
\hline PPROM at $<34$ weeks & $65(35.9)$ & $57(47.9)^{*}$ & $30(32.3)^{*}$ & 0.04 \\
\hline 1 & $32(17.7)$ & $20(16.8)$ & $8(8.6)$ & \\
\hline 2 & $131(72.4)$ & $82(68.9)$ & $75(80.6)$ & \\
\hline Composite adverse neonatal outcome & $43(23.8)$ & $29(24.4)$ & $22(23.7 \%)$ & 0.99 \\
\hline
\end{tabular}

Data are given as median (interquartile range) or $n(\%)$. Kruskal-Wallace and $\chi^{2}$ test were used as appropriate. GA, gestational age; PPROM, preterm premature rupture of membranes. * Post hoc tests.

this would not be a fair comparison; rather, we chose to report the great-circle distance between GPS locations as well as the rural status of the patients' location of origin. Although the mode of transportation was not systematically collected, the most likely transportation method was by land for group 1, both by land and air travel for group 2 , and by air travel for group 3 . The possible conclusion to be made is that differences in air travel do not affect the outcomes of TTTS after FLP. These findings are consistent with a smaller study from a European center [12].

There are a few potential weaknesses of our study. Due to the limited follow-up of the outcomes that were collected, we are unable to draw any conclusions about longterm neonatal morbidity such as neurologic sequelae. Additionally, we did not have information about potential maternal morbidity associated with travel in pregnan$\mathrm{cy}$, such as the incidence of venous thromboembolism in the postoperative period. Furthermore, ours is not the only fetal treatment center in Houston, TX that provides placental laser ablation for TTTS. It is possible that proximity to another major center within the same city or the existence of additional more distant regional centers may affect the composition of patients who are referred for evaluation. This may explain why fewer patients in groups 2 and 3 resided in urban areas when compared to group 1 and may reflect some of the differences in racial composition seen between the groups. Although racial and ethnic disparities are clearly associated with poor health outcomes in women's health [27], pregnancy outcomes in our groups were similar, with the exception of PPROM at $<34$ weeks. It is unclear why the difference in PPROM at $<34$ weeks was highest between groups 2 and 3 as this trend does not correlate with the differences seen in race and rural status. Ultimately, there appears to be no effect on GA or the number of neonatal survivors.

Socioeconomic status was not analyzed in this study, which is a potential source of bias. It is possible that patients in groups 2 and 3 represented individuals with the financial means to (1) seek care at the center of their choice and (2) travel great distances on short notice, often by plane. The alternative, that patients in these groups represented a population of individuals with limited means without any regional access to care, is also possible. As both socioeconomic and rural status are correlated with health literacy and access to care, this may have influenced the effect of distance on delivery outcomes [28].

The major strength of this study is the size of the patient cohort and range of DTs (minimum distance 3.5 miles, maximum distance 1,917 miles). Additionally, treatment and evaluation methods and providers remained constant during the study period, ensuring similar care among patients treated at TFC.

\section{Conclusion}

Our results suggest that in cases of TTTS, DT to a major fetal center does not affect GA at delivery or the number of neonatal survivors. Given the recent trends in healthcare to reduce unnecessary spending, prioritizing surgical experience over geographic proximity to care appears to be a safe strategy to consolidate healthcare resources without compromising patient outcomes in TTTS. 


\section{Statement of Ethics}

The study protocol was approved by the Institutional Review Board (HSC-MS-13-0712). Patients consented to prospective collection of outcomes from their respective delivery hospital.

\section{Disclosure Statement}

The authors have no conflicts of interest to declare.

\section{Funding Sources}

The study was not funded.

\section{Author Contributions}

E.P. Bergh, R. Donepudi, K.J. Moise Jr., A. Johnson, and R. Papanna contributed to patient recruitment, data collection, and manuscript preparation. E.P. Bergh and C.S. Bell performed statistical analysis and manuscript preparation.

\section{References}

1 Lewi L, Cannie M, Blickstein I, Jani J, Huber A, Hecher K, et al. Placental sharing, birthweight discordance, and vascular anastomoses in monochorionic diamniotic twin placentas. Am J Obstet Gynecol. 2007 Dec; 197(6):587.e1-8.

2 Sebire NJ, Snijders RJ, Hughes K, Sepulveda W, Nicolaides KH. The hidden mortality of monochorionic twin pregnancies. Br J Obstet Gynaecol. 1997 Oct;104(10):1203-7.

3 NAFTNet. Multiple Gestations 2018. Available from: www.naftnet.org.

4 Akkermans J, Peeters SH, Middeldorp JM, Klumper FJ, Lopriore E, Ryan G, et al. A worldwide survey of laser surgery for twintwin transfusion syndrome. Ultrasound $\mathrm{Ob}-$ stet Gynecol. 2015 Feb;45(2):168-74.

5 Kornelsen J, Stoll K, Grzybowski S. Stress and anxiety associated with lack of access to maternity services for rural parturient women. Aust J Rural Health. 2011 Feb;19(1):9-14.

6 Kornelsen J, Grzybowski S. The Costs of Separation. Can Womens Stud. 2005;24(1):7580.

7 Pasquier JC, Morelle M, Bagouet S, Moret S, Luo ZC, Rabilloud M, et al. Effects of residential distance to hospitals with neonatal surgery care on prenatal management and outcome of pregnancies with severe fetal malformations. Ultrasound Obstet Gynecol. 2007 Mar;29(3):271-5

8 Cannegieter SC, Rosendaal FR. Pregnancy and travel-related thromboembolism. Thromb Res. 2013 Jan;131 Suppl 1:S55-8.

9 Izadi M, Alemzadeh-Ansari MJ, Kazemisaleh D, Moshkani-Farahani M, Shafiee A. Do pregnant women have a higher risk for venous thromboembolism following air travel? Adv Biomed Res. 2015 Feb;4(1):60.

10 Chibber R, Al-Sibai MH, Qahtani N. Adverse outcome of pregnancy following air travel: a myth or a concern? Aust N Z J Obstet Gynaecol. 2006 Feb;46(1):24-8.

11 Magann EF, Chauhan SP, Dahlke JD, McKelvey SS, Watson EM, Morrison JC. Air travel and pregnancy outcomes: a review of preg- nancy regulations and outcomes for passengers, flight attendants, and aviators. Obstet Gynecol Surv. 2010 Jun;65(6):396-402.

12 Tchirikov M, Oshovskyy V, Steetskamp J, Thäle V. Neonatal outcome following longdistance air travel for fetoscopic laser coagulation treatment of twin-to-twin transfusion syndrome. Int J Gynaecol Obstet. 2012 Jun; 117(3):260-3.

13 Papanna R, Block-Abraham D, Mann LK, Buhimschi IA, Bebbington M, Garcia E, et al. Risk factors associated with preterm delivery after fetoscopic laser ablation for twin-twin transfusion syndrome. Ultrasound Obstet Gynecol. 2014 Jan;43(1):48-53.

14 Papanna R, Johnson A, Ivey RT, Olutoye OO, Cass D, Moise KJ. Laparoscopy-assisted fetoscopy for laser surgery in twin-twin transfusion syndrome with anterior placentation. Ultrasound Obstet Gynecol. 2010 Jan;35(1): 65-70.

15 Hijmans RJ. Geosphere: Spherical Trigonometry. R package version 15-7. 2017. Available from: https://CRAN.R-project.org/ package $=$ geosphere.

16 Center for Rural Health, School of Medicine \& Health Sciences, University of North Dakota. Guidelines for using rural-urban classification systems for public health assessment. Available from: https://ruralhealth.und.edu/ ruca [accessed February 8, 2019].

17 Team RC. A Language and Environment for Statistical Computing. R Foundation for Statistical Computing; 2019.

18 Morris RK, Selman TJ, Harbidge A, Martin WI, Kilby MD. Fetoscopic laser coagulation for severe twin-to-twin transfusion syndrome: factors influencing perinatal outcome, learning curve of the procedure and lessons for new centres. BJOG. 2010 Oct;117(11):1350-7.

19 van Klink JM, Koopman HM, van Zwet EW, Middeldorp JM, Walther FJ, Oepkes D, et al. Improvement in neurodevelopmental outcome in survivors of twin-twin transfusion syndrome treated with laser surgery. Am J Obstet Gynecol. 2014 Jun;210(6):540.e1-7.
20 Papanna R, Biau DJ, Mann LK, Johnson A, Moise KJ Jr. Use of the Learning Curve-Cumulative Summation test for quantitative and individualized assessment of competency of a surgical procedure in obstetrics and gynecology: fetoscopic laser ablation as a model. Am J Obstet Gynecol. 2011 Mar;204(3):218. e1-9.

21 Peeters SH, Van Zwet EW, Oepkes D, Lopriore E, Klumper FJ, Middeldorp JM. Learning curve for fetoscopic laser surgery using cumulative sum analysis. Acta Obstet Gynecol Scand. 2014 Jul;93(7):705-11.

22 Taylor MJ, Govender L, Jolly M, Wee L, Fisk NM. Validation of the Quintero staging system for twin-twin transfusion syndrome. Obstet Gynecol. 2002 Dec;100(6):1257-65.

23 Donepudi R, Papanna R, Snowise S, Johnson A, Bebbington M, Moise KJ Jr. Does anemiapolycythemia complicating twin-twin transfusion syndrome affect outcome after fetoscopic laser surgery? Ultrasound Obstet Gynecol. 2016 Mar;47(3):340-4.

24 Gratacós E, Ortiz JU, Martinez JM. A systematic approach to the differential diagnosis and management of the complications of monochorionic twin pregnancies. Fetal Diagn Ther. 2012;32(3):145-55

25 Ravelli AC, Jager KJ, de Groot MH, Erwich JJ, Rijninks-van Driel GC, Tromp M, et al. Travel time from home to hospital and adverse perinatal outcomes in women at term in the Netherlands. BJOG. 2011 Mar;118(4):45765.

26 Onega T, Duell EJ, Shi X, Wang D, Demidenko E, Goodman D. Geographic access to cancer care in the U.S. Cancer. 2008 Feb;112(4): 909-18.

27 ACOG Committee Opinion No. ACOG Committee Opinion No. 649: Racial and Ethnic Disparities in Obstetrics and Gynecology. Obstet Gynecol. 2015 Dec;126(6):e130-4.

28 ACOG Committee Opinion No. ACOG Committee Opinion No. 586: health disparities in rural women. Obstet Gynecol. 2014 Feb;123(2 Pt 1):384-8. 